\section{Clean rooms}

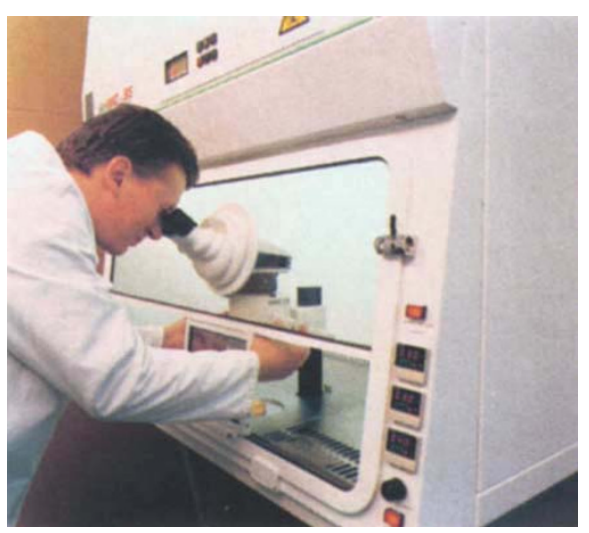

\section{Microscopic cabinet}

Problems with fitting microscopes inside cabinets have been overcome with the MicroMAT from Medical Air Technology (Manchester, UK). This class II safety cabinet incorporates a Leica MZ8 high-powered microscope, while ensuring full protection for both the operator and the sample. The cabinet, which has been designed around the microscope, still has accurate air-flow control and allows for high levels of cleanliness and low levels of contamination.

Tel: +44161320 5652

Fax: +441613350313

RSN: 1027

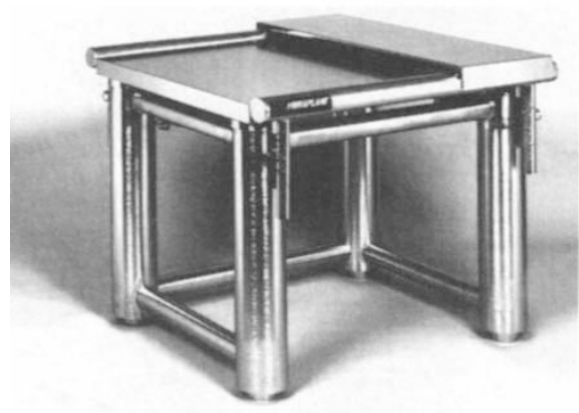

\section{Vibration isolation workstation}

Kinetic Systems' (Boston, MA) Vibraplane Lab Mate III is a class I cleanroom-compatible vibration isolation workstation. Stainless steel construction with welded tubular braces provides a minimum amount of horizontal surface, limiting the collection of airborne particulate. It has a completely closed isolation module and uses stainless steel valves with vented exhaust. Currently available for 800 or $1300 \mathrm{lb}$ applications, the Lab Mate III has 12 size/weight configurations.

Tel: +6175228700

Fax: +6175226323

RSN: 1028

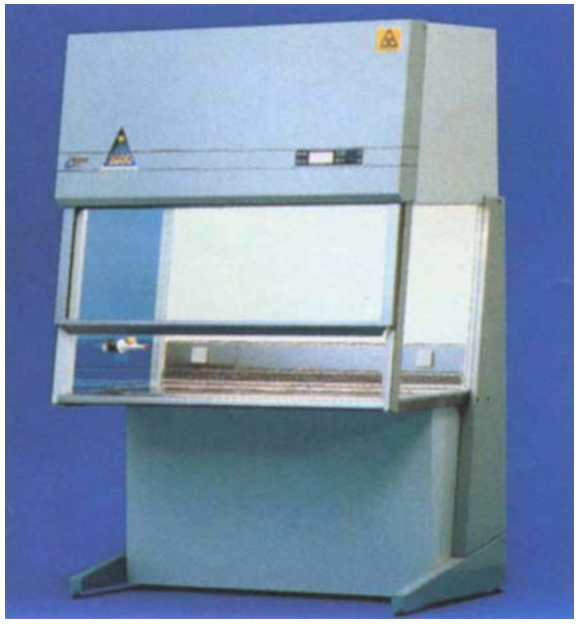

components are double-bagged, labeled, and shipped to the customer, where final assembly in a clean setting ensures that it remains a class I chair or stool. Class I ${ }^{\mathrm{Max}}$ seating is also available, with options such as ergonomic seats, backrest tilts, and air exchange systems.

Tel: +4198231089

Fax: +419 8231342

RSN: 1030

\section{Sterile third bag}

Sterile sample transportation in and out of clean rooms has been made more reliable with Becton Dickinson Microbiology Systems'(Meylan, France) inclusion of a third sterile bag within the sealed double-bag packaging. This third bag has been designed for use as a transport container for removing samples from the cleanroom, protecting both the sample and the clean room. The gamma-irradiated BBL Sterile Pack Prepared Media come with six types of RODAC plates, either $100 \mathrm{~mm}$ or $150 \mathrm{~mm}$.

Tel: +33476416464

Fax: +33076412124

RSN: 1031

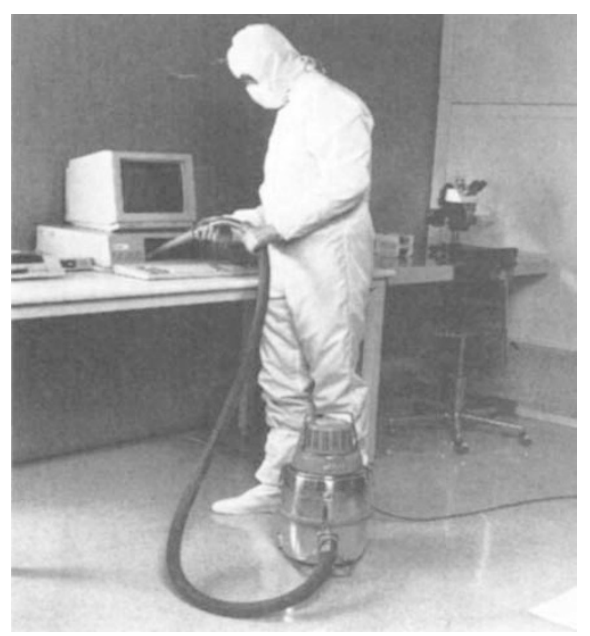

\section{Vacuum cleaning}

The GS 80 vacuum fromNilfisk of America (Malvern, PA) is ideal for clean room maintainance because it features a 4 -stage filtration system that includes a 2.25-gallon capacity disposable paper bag, an extra-large main filter, an optional microfilter, and an optional HEPA or ULPA filter. It is interference-suppressed and comes equipped with a motor thermal protection device that prevents overheating caused by unclean filters or accidental blockage in a nozzle or hose.

Tel: +610 6476420

Fax: +6106476427

RSN: 1032 